The Claims Culture; A Taxonomy of Attitudes in the Industry

John Rooke, David Seymour \& Richard Fellows

Published as:

Rooke, J., Seymour, D. \& Fellows, R. (2003) 'The Claims Culture; A Taxonomy of Industry Attitudes', Construction Management and Economics, 21(2):167-174. 


\title{
The Claims Culture; A Taxonomy of Attitudes in the Industry
}

\author{
Abstract \\ This paper presents an analysis of a familiar aspect of construction industry culture \\ which we have dubbed 'the claims culture'. This is a culture of contract \\ administration that lays a strong emphasis on the planning and management of \\ claims. The principal elements of the analysis are two sets of distinctions. The \\ first of these comprises economic and occupational orders, referring to two kinds \\ of control that are exercised over the construction process; predicated respectively \\ on economic ownership and occupational competence. The second, refers to \\ contrasting attitudes towards relationships and problem solving within these \\ orders: respectively 'distributive’ and 'integrative’. The concepts of economic \\ and occupational order entail further sub-categories. The various attitudes \\ associated with these categories and sub-categories are described. They are \\ assessed as to their consequences for change initiatives in the industry.
}

Keywords: Culture; Claims Management; Procurement; Ethnography; Grounded Theory. 


\section{Introduction}

This paper describes an aspect of industry culture: attitudes relating to the occurrence of claims in the administration of contracts. Drawing on findings and analysis from three ethnographic studies, it is intended to provide guidance for the management and reform of contractual relations.

The idea that the industry has a culture which is opportunistic, prone to conflict and resistant to change is a byword in construction. It was argued in the Tavistock studies some forty years ago, that subscription to the economic principle of competition results in a fragmented system of economically independent units, each attempting to maximise its benefit, to the detriment of the co-operation required of a technically interdependent system, if collective benefit is to be achieved. To compensate for the structured irrationality of formal systems, an adaptive system and a system of personal relationships, it was argued, enable a tolerable level of performance. People, in other words, draw on what resources they can to make the best out of a bad job, to get by and get things done.

Our research suggests that there is still some justice in this characterisation. However, we propose a conception of 'claims culture' which seeks to balance the implicit judgmental component that occurs in much of the construction management literature whenever culture is cited. Consider, for instance, this classic quotation from a builder in the Tavistock study.

"I do find quite frequently when I go on a site that the poor wretched foreman, who has no access to contract drawings and things that may be filed away in a safe, is just building from the wrong drawings. How is he to know? [However,] I for one would not be put out if I found my foremen working to a set of drawings totally different from the contract drawings. I 
would start sharpening my pencil and think of all the extras I could claim as a consequence. It is on these items that we make our money.” (Higgin and Jessop 1965 p33)

The reader is asked to reflect on his/her own response to this. We think it is likely to provoke ambivalence. On one hand, this is the kind of opportunism which is condemned when there is talk of changing culture for the better. On the other, it bespeaks a perfectly rational and legal adaptation.

This highlights the dilemma of treating culture in management studies. Because management studies are about how to do things better, there is a danger of assuming the existence of a self-evidently desirable Best Practice. Thus, 'getting the culture right', a phrase frequently heard, is seen as a matter of changing 'hearts and minds' so as to be receptive to such Best Practice. Green $(1997,1998)$ has rightly challenged the hegemony given in the very language of management studies, which allows such value judgements to be smuggled into what are offered as objective studies.

Peters and Waterman have done much to popularise this Best Practice view: "Without exception, the dominance and coherence of culture proved to be an essential quality of the excellent companies. Moreover, the stronger the culture and the more it was directed toward the marketplace, the less need was there for policy manuals, organization charts, or detailed procedures and rules. In these companies, people way down the line know what they are supposed to do in most situations because the handful of guiding values is crystal clear.” (Peters \& Waterman 1982, p76)

This quote displays not only the importance which the authors attach to culture, but also the weakness of the way they conceive it. They recognise the vital role 
that culture plays in providing implicit understandings and agreements over a whole range of issues which facilitate efficient organisation. What is missing is the sense of culture as a ubiquitous and necessary phenomenon. Culture is not something that an organisation either possesses or lacks. Nor is it something which can be imposed on an organization, simply by propagating the right stories and slogans. On the contrary, a major finding of the research reported here is that far from lacking a strong culture, construction contractors possess a deeply ingrained and powerful one. It is the nature of this culture that constitutes the problem for reformers.

Anthony (1994) has criticised the consultant-led interest in managing culture, showing how in several cases, this project has failed. Hickman and Silva (1984) introduce a distinction between strategy and culture which would seem to explain these failures, conceiving culture as a largely conservative force, balancing the innovative thrust of strategic thinking. They identify two skills which they see as essential to successful change management: 'creative insight', relating to the ability to formulate effective strategy; and 'sensitivity', relating to the ability to recognise and negotiate the existing culture. The latter is concerned with understanding other people's points of view: it is this understanding that enables successful management of company cultures. It is also this understanding that ethnographic research aims to achieve and this paper intends to inform.

Seen from this perspective, the supposed culture change initiatives criticised by Anthony were not in fact attempts to change culture, but rather to impose strategy with little regard for existing culture. The taxonomy proposed here aims to make explicit the intrinsic moral and judgmental content of culture and thereby avoid this error. 
Its principle elements are two sets of distinctions. First, economic and occupational orders, referring to two kinds of control that are exercised over the construction process; predicated respectively on economic ownership and occupational competence. Second, distributive and integrative attitudes, defining a general orientation towards relationships and problem solving within these orders. These distinctions combine to give the four categories illustrated in Table 1. These are considered in turn below and further distinctions, integral to the two orders, are introduced. Thus, the following categories are described:

- distributive attitudes of both contractors and clients to the economic order;

- two integrative attitudes of contractors to the economic order, those of engineers and customer-centred managers;

- the integrative attitude of clients to the economic order;

- distributive attitudes to the occupational order of economically integrative engineers;

- a possible integrative attitude to the occupational order.

TABLE 1 ABOUT HERE

\section{Methodology}

Ethnographic research, involves the researcher interacting with and 'getting to know' the people whose culture is to be studied. This involves a recognition that the methods a researcher uses to learn a culture are in principle no different from those used by members of that culture. These methods have been described by 
Garfinkel (1984, especially pages 89-94) under the collective term 'documentary method' and introduced to the construction management literature by Rooke (1997). They are characteristic of the interpretative approach recommended by Seymour and Rooke (1995).

The data used here are from two research projects. The first of these, reported more fully in Seymour (1986) addressed the application of organization theory to the study of construction companies. The second, early findings from which were published in Rooke \& Seymour (1995), focussed more directly on the cultural context of contract administration. Both studies involved a combination of interviews and periods of direct observation of industry personnel at work. In the former study interviews were semi-structured, based on a check list of between four and six open ended questions. In the latter, they were completely unstructured: the respondents were asked a general question about their experience of contract administration; supplementary questions were only asked when they were necessary to keep the respondent talking.

The analysis was completed during the course of a third research project, as part of a wider exercise to analyse industry culture. A grounded theory approach was adopted, in which concepts are generated inductively from the data (Glaser \& Strauss 1967, Strauss \& Corbin 1998, Charmaz \& Mitchell 2000). This involves a process in which data is coded according to concepts developed simultaneously with the coding process and the data collection. Thus, the three processes (coding, concept development and data collection) are mutually informing, allowing the research design to evolve as the analysis progresses and concepts to be adjusted in the light of new data. The approach has previously been applied to construction management issues by Dainty, Bagilhole \& Neale (2000) who have 
used it to produce an account of women's under-achievement in the industry and by Dainty, Briscoe \& Millet (2001) who apply it to supply chain issues.

One facet of the presentation of findings here departs from a strict application of the principles of grounded theorizing, by presenting the key categories in the form of a logically generated two by two grid. This results in the production of one category (integrative/occupational) that is not empirically substantiated. This category may be regarded as a working hypothesis which requires confirmation through further data collection or analysis.

\section{Economic and Occupational Orders}

We suggest that culture is usefully approached via the concept 'order' which implies that people:

* expect and depend upon more or less stable and understandable patterns of conduct from others.

Furthermore, they recognise that:

* there are values and rules that govern this conduct;

* that rules imply control, which may be enacted through particular individuals, whose identity is provided for by those same rules.

Economic and occupational orders are identified in the taxonomy as two such sets of expectations and recognitions that operate in the construction industry (and elsewhere). The occupational order is constituted by those rights of control that are distributed amongst occupational specialisms whose work produces economic benefit or value. These rights are distinct from those provided in the contractual arrangements that an individual or a company make when they enter into a 
contract. These contractually determined rights, which relate to the way in which benefit is distributed, are identified as the economic order.

Birch illustrates the coexistence of the economic and occupational orders by reference to a lump sum contract for a house extension, the contractors being two brothers and the employer being the house owner. The brothers subcontracted many tasks to others and regularly subordinated themselves to the authority of these specialists. Thus,

"when it came to the electrical work, it was the self-employed electrician who decided how the work should be done, with one of the brothers (main contractor) acting as his labourer, accepting the electrician’s instructions in a field in which he acknowledged himself to be a non-expert [...] On other occasions, the brothers proposed a design modification more appropriate than the solution offered by the architect: the extension was slightly widened to make possible the use of a standard door-size; [...]” (Birch cited in Seymour 1986, p22)

Thus, while people relate to one another according to the principle of ownership of economic resources and the maximisation of self-interest (economic order), there is also mutual orientation to the principle of expertise and effective working practice (occupational order).

While these orders coexist in the governance of everyday conduct, they sometimes come into conflict. Thus, in one case observed, foundation works were underway on a contract when water started to pour into the excavation from the sides of the cutting. The contractor's site agent, anxious to minimize the delay caused by the flooding, informed the resident engineer on site and immediately ordered a pump to clear the excavation of water. Later the same day, the contractor's surveyor 
instructed the agent to cancel the order. When the agent protested that the work could not go ahead without the pump, the QS dismissed the objection as of minor importance. The vital issue was that the RE authorize the pump and thus make clear the client's liability to pay for it.

\section{Distributive and Integrative Attitudes}

The terms distributive and integrative are borrowed from the field of negotiation studies, where they describe alternative strategies of negotiation (Bisno 1988, Farnham \& Pimlott 1995). The distributive strategy,

"is based on the assumption that opposing goals, interests, or preferences are at stake and that the most effective method of attaining one's objectives is to try to secure concessions from the other party” (Bisno 1988, p100)

In contrast, the integrative strategy,

"may be viewed as an approach that emphasises negotiating outcomes that are mutually advantageous, although not necessarily of equal benefit to both parties. It stresses problem solving and the creative development of new solutions.” (Bisno 1988, p102-3)

The concept 'attitude' has wider implications than that of 'strategy'. The latter is a course of action that a negotiator might choose to take, the former implies, among other things, a propensity to choose one kind of strategy over another. It is noticeable that the distributive attitude, unlike the distributive strategy, is truly adversarial, consisting in an aggressive stance towards those 'on the other side' of a contractual or occupational divide. The language in which this attitude is often expressed, is far from one of compromise; the talk is of 'defending oneself from', 
or 'getting one over' the 'opposition'. In contrast, the integrative attitude to the economic order is always, in practice, ambivalent. While creative problem solving to achieve win-win solutions is the preferred mode of negotiation, the threatening reality of the claims culture is always a sobering presence.

\section{Attitudes to the Economic and Occupational Orders}

If economics is concerned with the allocation of scarce resources, then it is a zero sum game and distributive attitudes are strongly implied. However, the wealth generating action of production makes it possible to conceive of economic solutions in terms of win-win scenarios. This kind of thinking lies behind concepts such as Partnering and the Engineering and Construction Contract (NEC) which anticipate the generation of savings to be shared by both parties to a contract.

The occupational order is generated by the division of labour which, in turn, is a function of the increasing capability of the production process. The underlying logic of such a division is articulated and integrative. However, misunderstandings, rivalries and resentments can arise between members of different occupational groupings.

Thus, though there is a strong relationship between the economic order and distributive attitudes on the one hand, and between the occupational order and integrative attitudes on the other, these relationships are by no means necessary. Table 1 summarises the relationships between orders and attitudes, demonstrating the four types of viewpoint that are logically possible. Below, we review the various attitudes to contractual relations that we have found in the industry, classified according to the categories of the two orders. For the purposes of this 
analysis, 'the client' is taken to include all members of the client's team, including consultants. The view points represented are ideal typical (Weber 1947), that is to say they are to be taken as points of comparison, to which the reality of industry culture can be compared at any actual instance; they are generalizations and it may be rare to find individuals who conform precisely to them.

\section{Distributive Attitudes to the Economic Order}

The quarrel over the pump cited above is a classic example of the claims culture. The attitude of the QS on this occasion is an expression of the economic order at its most distributive. The 'contractual divide' is central to the claims culture, providing for two categories of distributive economic attitude: contractor and client.

\section{Distributive Contractors}

The viewpoint of the distributive contractor may be represented as follows. The client is out to get the best possible deal by 'screwing' the contractor at every opportunity. It is therefore both necessary and just that the contractor should adopt the same approach. Since clients are stupid as well as greedy, by and large, contractors will get the better of them. A combination of heavy price competition and inadequate design and method statements means that contractors must quote for low or non-existent profit margins. This is so because any opportunity to increase income by exploiting omissions or mistakes in the contract data, will be used by competitors and be reflected in tender prices. This practice effectively 
punishes the client for sloppy design work, since a well thought out design specification will provide no opportunities for claims.

The attitude as portrayed here has a strong emotional and moral content. The emotional content has two aspects: resentment of client's unfair practices; and contempt for their ability to plan and manage projects. The two often go hand in hand. Indeed, a client's incompetence, by causing difficulties for the contractor, can simultaneously be a source of both resentment and contempt. Another ground for resentment is the feeling that contractors work harder than 'the other side'. This is particularly felt at site level, where contractors can see the hours worked by Resident Engineers and compare them with the hours they themselves work.

However, the attitude can exist without apparent negative feelings. For instance, one contractor talked for two hours about contractor client relationships, stressing their adversarial nature, without displaying any negative feelings. His attitude was pragmatic; he knew the rules of the claims culture and played by them almost with pleasure. Where bitterness accompanies the distributive attitude, it is stronger and more common among distributive engineers than distributive commercial managers.

The moral content of the distributive attitude has three aspects. First, opportunistic practices are to be expected and are excusable: given the economics of contracting, the contractor has no choice but to plan for and pursue claims. Second, these practices, rather than being disreputable are actually beneficial in that they act as a control over the standards of consultants' work: claims punish bad design and planning. Third, far from being innocent parties, clients are themselves guilty of unfair practices, in withholding or delaying payments which are due to the contractor. 
The third argument is the most common. It is pointed out that clients have ample opportunity to delay payments and will do so for their own reasons, to ease their own cash flow situation, for instance. Furthermore, they are capable of causing severe problems for contractors who successfully object. As one contractor's site engineer put it:

“At the end of the day, my job, how easy it is, can rest an awful lot on the person and the persons that are involved on that site. 'Cos they can go out there and say 'I'm stopping that, you're working unsafe there, I'm going over there, I'm condemning that, you've got a bit of clay in the capping layer, I’m going over there, you've got men working in an unsafe fashion, that concrete's not to spec, you've added water to it'. They can do that.”

\section{Distributive Clients}

The attitude of the distributive client may be characterised as follows. The aim of procurement is to get the job done as cheaply as possible, the contractor's profit is not a consideration. Contracts should be designed to bind the contractor hand and foot, for contractors will cheat the client if they can.

In contrast to the attitude of the distributive contractor, the moral and emotional contents of this attitude are less explicit in the characterisation offered. However, they are implicit in the accounts offered by clients. The morality here is the morality of the market; the customer is entitled to seek the lowest price for a specified commodity and to expect that that commodity conforms to the specifications. In failing to deliver construction projects at the tender price, contractors are cheating; they are finding loopholes and playing tricks. This is the starkest difference between the two attitudes; what, for the contractor, are 
justifiable mechanisms for managing incomplete design work in a competitive environment are, for the client, devious methods of generating profit without production.

Distributive clients do not acknowledge the bitterness among contractors. They dismiss contractors' complaints about unprofitable contracts with the argument that contractors will always plead poverty. After all, the contractors' profitability is their own business, not the client's. Even where the unprofitability of a contract is recognised, this is clearly attributed to the contractor's own culpability: they have 'bought the contract' by bidding too low and are now seeking to increase the price by illegitimate means.

Where the attitude manifests an emotional content, it is one of suspicion, defensiveness, sometimes even paranoia: a feeling of vulnerability to the contractor's trickery and an uncomfortable uncertainty as to what trick might be attempted next.

\section{Integrative Attitudes to the Economic Order}

The other two points of view identified as elements of the claims culture are those of the integrative contractor and client. These are more peripheral to the culture, representing the attitudes of those involved with its practices, but not necessarily committed to them. It is among those with an integrative attitude to the economic order that change initiatives may originate and find support. Indeed, contemporary management theory, by placing customer requirements at the centre of its analysis, advocates an integrated economic order. Management philosophies such as Partnering and Total Quality typify this attitude. 
Apart from the emphasis on co-operation and win-win solutions, the outstanding feature of this attitude, as it is found in the industry, is its defensiveness; however integrative individuals might be, they are forced to recognise the threat posed to their approach by the existence of the distributive attitude.

\section{Integrative Contractors}

Our research has identified two types of integrative contractor, the views of both may be summarized as follows. The aims relating to any project are to do a good job, on time and at contract price. The best way to achieve this is through developing co-operative relationships with the client, which contribute to a more pleasant and efficient working relationship. Nevertheless, profitability is an issue of survival and where it is threatened, overshadows other considerations. Integrative contractors will try to avoid unprofitable contract prices, but may be forced by competition to become claims conscious.

\section{Integrative Contractors’ Engineers}

Integrative economic attitudes among contractor's engineers have the following four characteristics: an interpretation of engineers' occupational rights such that they encompass economic issues; feeling that engineers’ occupational rights are diminished by the claims culture; a contemptuous attitude to quantity surveyors; a defensiveness regarding clients’ attitudes.

Contractors' engineers who express an integrative attitude to the economic order tend to have a wide interpretation of an engineer's competence and responsibility to encompass the control of costs. This is exemplified in the expression: 'an 
engineer is someone who can build for ten pounds what any damn fool can build for a hundred'.

Economically integrative engineers can also tend to be idealistic, wishing to see an end to the claims culture, which they perceive as interfering with the effectiveness of the construction process. This feature is closely connected to their professional rivalry with quantity surveyors.

However, this integrative attitude among contractors' engineers is severely constrained by practical concerns. Short term profit is an overriding factor. Two factors determine this outlook, the need for project managers to show a profit on each project and the need for companies to show a positive return to stockholders. As one integrative engineer put it:

"If you get to the end of a job and you've made a loss, you look at bloody everything, to see if there are any commercial opportunities you've missed.”

\section{Customer Centred Managers}

Some managers in contracting, at all levels from site engineers to directors, see a prime objective as being to 'get along with the client'. Indeed, some speak of their ability to foster good relations with the client as the key feature of their role. However, the important thing to note about this attitude is that, unlike that of the integrative engineer described above, it is fundamentally conservative; it is complementary to, rather than opposed to, the distributive attitude. These customer centred managers accept the necessity for claims and see their role as being to manage the tensions created by them. 


\section{Integrative Clients}

Integrative attitudes among clients’ representatives were more difficult to uncover. Some spoke of having sympathy for the contractors' problems, but it was not clear whether this had an effect on their practice. However, some expressed the opinion that contractors' profitability is essential to the health of the project and to the industry as a whole and that fair-minded contractors will act in a reasonable manner, if they are treated fairly. Nevertheless, this tended to be qualified by the observation that many contractors will attempt to 'put one over' on the client and this possibility must be guarded against.

Examples were found where integrative attitudes were expressed on both sides of negotiations and, although the inevitable consequences of the claims culture played themselves out, the participants performed their parts with good will and humour. In these cases it was the integrative interpersonal skills exhibited by project participants that made the project successful despite the claims.

\section{Distributive Attitudes to the Occupational Order}

Although economic attitudes are central to the claims culture, occupational attitudes, particularly distributive ones, are also relevant. In particular, the following should be noted.

- Economically integrative engineers regularly display distributive attitudes to other professions, particularly QSs.

- Site engineers often resent non- site personnel. Often, integrative attitudes will predominate between contractor's and client's engineers on site, while distributive imperatives are begrudgingly accepted from the ‘desk jockeys’ at 
head office. In this way, site engineers can work amicably together, while attributing blame for contractual difficulties to others.

\section{An Integrative Attitude to the Occupational Order?}

An integrative attitude to the occupational order was rarely observed. However, this may be because such attitudes are so fundamental to the occupational order as to be invisible. It is expected that a closer analysis of the data will reveal subtle indications of such attitudes.

\section{Discussion: Attempting to Change the Culture}

Change initiatives in the industry tend to conform to current mainstream management thinking in that they are customer centred in their inspiration. This philosophy evaluates business processes according to how they contribute to products and/or services that satisfy customer needs. The argument is, that a company that satisfies its customers earns a good reputation and therefore wins orders, thus earning profit. While the logic and relevance of this cannot be denied, it is important to recognise that the economic interests of other players in the supply chain are significant motivators that sometimes contradict the customer service ethic. 


\section{The Value of the Claims Culture}

The value of important aspects of the claims culture must be recognised. The problems for contractors wishing to follow the customer centred philosophy are as follows.

- As long as price competition dominates at tender stage they will face the danger of losing out to less scrupulous competitors who will find ways of increasing the out-turn price. 
- Planning for claims is a defence against bad design.

- Companies and individuals now have a massive investment in claims planning.

- Planning for claims is a defence against onerous transfers of risk to the contractor.

- Even if procurement arrangements change to accommodate less adversarial relations, contractors cannot be sure that this will become a permanent state of affairs.

These issues must be addressed if any change initiative is to be successful.

\section{Conservatism}

In addition, proponents of change must overcome sheer cultural inertia. Although economic necessity can be seen as a driving force behind the growth of the claims culture, once established a culture has a dynamic of its own; the administration of claims has taken its own place in the occupational order. Furthermore, a culture does not disappear, even when its practices fall into abeyance. These can be quickly resurrected if people think that circumstances warrant it. Nor do attitudes necessarily change when behaviour does. The expertise associated with claims management and the distributive attitudes that accompany it will remain in the industry, at least for some considerable time.

INSERT TABLE 2 ABOUT HERE 


\section{Forces of Change and Resistance}

Table 2 provides a tool for identifying the forces of change and resistance that exist within the industry. The main points to be noted are.

- Distributive economic attitudes are at the core of the claims culture. The archetypes of the distributive client and contractor are the two elements that make up a culture of conflict. Individuals holding these views are not likely to be sympathetic to change.

- There are two types of economically integrative individual.

- Conservative integrative attitudes are complementary to the claims culture. Managers displaying these attitudes are concerned with maintaining good relationships within the claims culture. They are likely to be unsympathetic to change.

- Radical integrative attitudes are found among engineers who promote engineering values above the values of claims culture. They see cost effective construction as the ideal and are likely to be sympathetic to, or actively supportive of, changes that promote this.

- Distributive occupational attitudes found among engineers are likely to be indicative of radical integrative attitudes to the economic order.

- Since integrative occupational attitudes are logically fundamental to a successful division of labour, distributive attitudes may also be problematic.

\section{The Occupational Order}

Finally, it is noted that there has been little focus here on integrative occupational attitudes. Furthermore, although such attitudes clearly contribute to the success 
of projects, we have found little mention of them in discussion of change initiatives in the industry at large. This is partly because it is assumed that if integrative contractual arrangements can be achieved, then the occupational order will automatically optimise itself. There is some justification for this view. The occupational order embodies the sum total of the scientific, technical and experiential knowledge of members of the industry, as well as the moral and self actualizing motivations to produce good work that lie at the heart of both trades and professions. There is good reason, therefore, to believe that, once liberated from the restricting influence of economic conflict, the occupational order will establish high standards of quality and efficiency. In particular, the basis for radically integrative occupational attitudes is provided in: the target contract approach; the insistence that partnering relationships contain provision for continuous improvement; the provision that internal partnering should precede partnering between companies. Measures such as these would, in turn, provide the conditions in which production management based initiatives such as Lean Construction can be successfully introduced. Thus, tackling the claims culture can be seen as a necessary first step towards improving productivity.

\section{Acknowledgements}

The research reported in this paper was partly funded by the Engineering and Physical Sciences Research Council (project numbers: GR/J90459 \& GR/M07564). The authors would also like to thank our referees for their constructive criticisms which have enabled us to substantially improve this paper and our many informants over the years, who have educated us in the ways of the industry. 


\section{References}

Anthony, P. D. (1994) Managing Culture, Open University Press, Buckingham. Bisno, H. (1988) Managing Conflict, Sage Publications, London.

Charmaz, K. \& Mitchell, R. G. (2001) 'Grounded Theory in Ethnography', in P. Atkinson, A. Coffey, S. Delamont, J. Lofland \& L. Lofland (eds.) Handbook of Ethnography, Sage, London.

Dainty, A. R. J., Bagilhole, B. M. \& Neale, R. H. (2000) 'A Grounded Theory of Women's Career Under-Achievement in Large UK Construction Companies', in Construction Management and Economics, 18 pp239-250.

Dainty, A. R. J., Briscoe, G. H. \& Millett, S. J. 2001 'Subcontractor Perspectives on Supply Chain Alliances' in Construction Management and Economics, 19 pp841-848.

Farnham, D. \& Pimlott, J. 1995 Understanding Industrial Relations, (5th Edition) Cassell, London.

Garfinkel, H. 1984 'Common Sense Knowledge of Social Structures: The Documentary Method of Interpretation in Lay and Professional Fact Finding', in Studies in Ethnomethodology, Polity Press, Cambridge.

Glaser, B. G. \& Strasuss, A. L. 1967 The Discovery of Grounded Theory; Strategies for Qualitative Research, Weidenfeld \& Nicholson, London. Green, S. D. (1998) 'The Technocratic Totalitarianism of Construction Process Improvement: A Critical Perspective', in Engineering Construction and Architectural Management, 5.4 pp. 376-386. 
Hickman, C. R. \& Silva, M. A. (1984) Creating Excellence; Managing

Corporate Culture, Strategy, and Change in the New Age, George Allen \& Unwin, London.

Higgin, G. W. \& Jessop, W. N. (1965) Communications in the Building Industry, Tavistock, London.

Maurer, R. (1996) Beyond the Wall of Resistance, Bard Books, Austin.

Peters, T. J. \& Waterman, R. H. (1982) In Search of Excellence, Harper and Row, London.

Rooke, J. (1997) 'Developing a More Empirical Approach to Culture, Attitude and Motivation in Construction Management Research: A Critique and a Proposal', Journal of Construction Procurement, 3.2: 45-55

Seymour, D. E. (1986) The Place of Organisation Theory in The Study of Construction Management, PhD Thesis, University of Birmingham.

Seymour, D. E., \& Rooke, J. A. (1995) 'The culture of the industry and culture of research’, in Construction Management and Economics, 13:511-523.

Sharrock, W. W. (1974) 'On Owning Knowledge’ in R. Turner (ed.)

Ethnomethodology, Penguin, Harmondsworth.

Strauss, A. \& Corbin, J. (1998) Basics of Qualitative Research: Techniques and Procedures for Developing Grounded Theory, (Second Edition) Sage, London. Weber, M. (1947) The Theory of Social and Economic Organisation, T. Parsons (ed.), A. M. Henderson \& T. Parsons (tr.), The Free Press, New York. Wrapp, H. E. (1984) ‘Good managers don’t make policy decisions’, Harvard Business Review, July-August 1984:8-21. 


\begin{tabular}{|c|c|c|}
\hline & economic order & Occupational order \\
\hline $\begin{array}{l}\text { distributive } \\
\text { attitude }\end{array}$ & $\begin{array}{l}\text { The core of the claims } \\
\text { culture. Expressed by both } \\
\text { contractors and clients in } \\
\text { interviews and practices and } \\
\text { summarized below in the } \\
\text { descriptions of distributive } \\
\text { clients and contractors. }\end{array}$ & $\begin{array}{l}\text { Denotes competition, } \\
\text { misunderstanding, or } \\
\text { resentment towards other } \\
\text { occupational groups. Found } \\
\text { among engineers, particularly } \\
\text { those supporting change } \\
\text { initiatives like the NEC. }\end{array}$ \\
\hline $\begin{array}{l}\text { integrative } \\
\text { attitude }\end{array}$ & $\begin{array}{l}\text { When found among } \\
\text { contractors' engineers, tends } \\
\text { to be antithetical to the } \\
\text { claims culture and conducive } \\
\text { to change initiatives such as } \\
\text { the NEC, but can be } \\
\text { complementary to the claims } \\
\text { culture, especially among } \\
\text { managers with a non- } \\
\text { engineering background. } \\
\text { Sometimes supportive of } \\
\text { change initiative when found } \\
\text { among clients' managers. }\end{array}$ & $\begin{array}{l}\text { Can be seen in the example of } \\
\text { the house extension given } \\
\text { above, but little overt evidence } \\
\text { of this attitude was found in the } \\
\text { research. }\end{array}$ \\
\hline
\end{tabular}

Table 1 Distributive and integrative attitudes to the economic and occupational orders 


\begin{tabular}{l|l|l} 
& economic order & occupational order \\
\hline $\begin{array}{l}\text { distributive } \\
\text { attitude }\end{array}$ & $\begin{array}{l}\text { The core of the claims } \\
\text { culture. Represents } \\
\text { attitudes and practices that } \\
\text { must be addressed by change } \\
\text { agents, whether they seek to } \\
\text { evade (Wrapp) or embrace } \\
\text { (Maurer) them. }\end{array}$ & $\begin{array}{l}\text { Although distributive attitudes } \\
\text { found in the research were } \\
\text { inevitably associated with } \\
\text { progressive forces, they must } \\
\text { be treated with some caution. } \\
\text { Rancour arising from such } \\
\text { attitudes may prove an } \\
\text { obstacle. }\end{array}$ \\
\hline $\begin{array}{l}\text { integrative } \\
\text { attitude }\end{array}$ & $\begin{array}{l}\text { Can be radical or } \\
\text { conservative. Radical } \\
\text { attitudes are the ideal that } \\
\text { advocates of the NEC and of } \\
\text { Partnering arrangements are } \\
\text { trying to achieve. } \\
\text { Conservative attitudes } \\
\text { complement the claims } \\
\text { culture and may present } \\
\text { difficulties to change agents. }\end{array}$ & $\begin{array}{l}\text { Clearly desirable, as } \\
\text { contributing to the success of } \\
\text { projects, but apparently not } \\
\text { addressed directly by industry } \\
\text { initiatives. It is therefore } \\
\text { always desirable to promote } \\
\text { these attitudes. }\end{array}$ \\
\hline
\end{tabular}

Table 2 A summary of forces of change and resistance within the industry 